\title{
Bleeding from portal biliopathy in situs inversus totalis
}

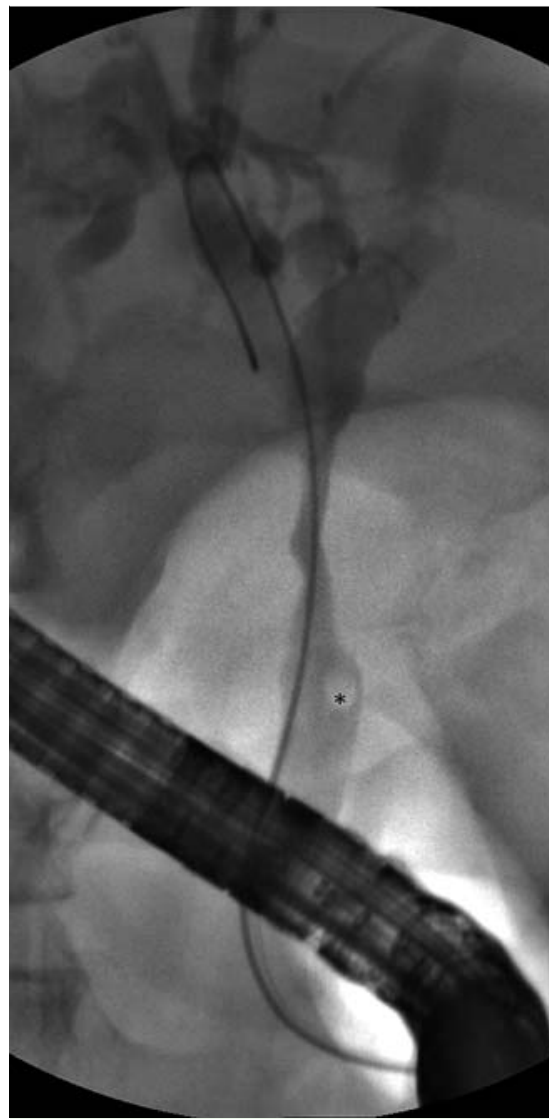

Fig. 1 A 43-year-old man presented with obstructive jaundice. Cholangiography, with the patient in prone position, showing smooth common bile duct/common hepatic duct compression and a small stone $\left({ }^{*}\right)$ within.

A 43-year-old male patient presented with obstructive jaundice. Blood samples showed total bilirubin $3.1 \mathrm{mg} / \mathrm{dL}$, direct bilirubin $2.0 \mathrm{mg} / \mathrm{dL}$, aspartate aminotransferase (AST) $261 \mathrm{U} / \mathrm{L}$, alanine transaminase (ALT) $165 \mathrm{U} / \mathrm{L}$, alkaline phosphatase 241 U/L. Coagulation, hemogram, albumin, and renal function test findings were within the normal range. Serological testing for hepatitis $B$ and hepatitis $C$ virus was negative. Abdominal ultrasonography and magnetic resonance imaging revealed situs inversus totalis, and a thrombosed portal vein with cavernoma, and common bile duct/common hepatic duct (CBD/CHD) obstruction.
Endoscopic retrograde cholangiopancreatography (ERCP) was performed with only minor changes to the standard technique, as highlighted in previous case reports $[1,2]$. Keeping the patient in the prone position (as used at our institution for ERCP in patients without situs inversus totalis), the endoscope short position was achieved by torquing the scope 180 degrees anticlockwise and the papilla was cannulated with a standard sphincterotome. The initial cholangiogram showed smooth CBD/CHD compression and a small stone within ( $\bullet$ Fig. 1 ). After a small biliary sphincterotomy, the biliary stone was extracted using a balloon. A sudden spurt of torrential bleeding came from the papilla, suggesting a rupture of intraductal varices ( $\bullet$ video 1 ). A $6-\mathrm{cm}$ biliary fully covered self-expandable metal stent (SEMS) (Boston Scientific, Natick, Massachusetts, USA) was immediately inserted, as described for bleeding from portal biliopathy in patients without situs inversus totalis ( $\bullet$ Fig. 2) [3]. Bleeding continued in spite of the biliary SEMS, and hence a $10-\mathrm{mm}$ diameter controlled radial expansion balloon (CRE; Boston Scientific) was inserted into the SEMS ( $\bullet$ Video 1). The balloon was kept inflated for 2 minutes at the partially expanded upper half of SEMS (where the likely choledochal varices were located based on ERCP imaging). There was no biliary bleeding at the end of balloon decompression and its removal and for further duodenoscopic observation for next five minutes ( $\bullet$ Video 1 ).

However 2 days after the procedure, the patient developed fever $\left(38^{\circ} \mathrm{C}\right)$ with a rise in bilirubin. A repeat ERCP showed biliary obstruction due to adherent clot ( Fig. 3a) and a 7-Fr 10-cm double-pigtail stent was placed within the SEMS ( $\bullet$ Fig.3b). After 3 months the SEMS along with the plastic stent was removed. No oozing occurred after SEMS removal. Another 7-Fr 10-cm double-pigtail stent was placed because of persistent biliary stricture ( Fig.4). No adverse events were reported at the 3-month follow-up after SEMS removal.

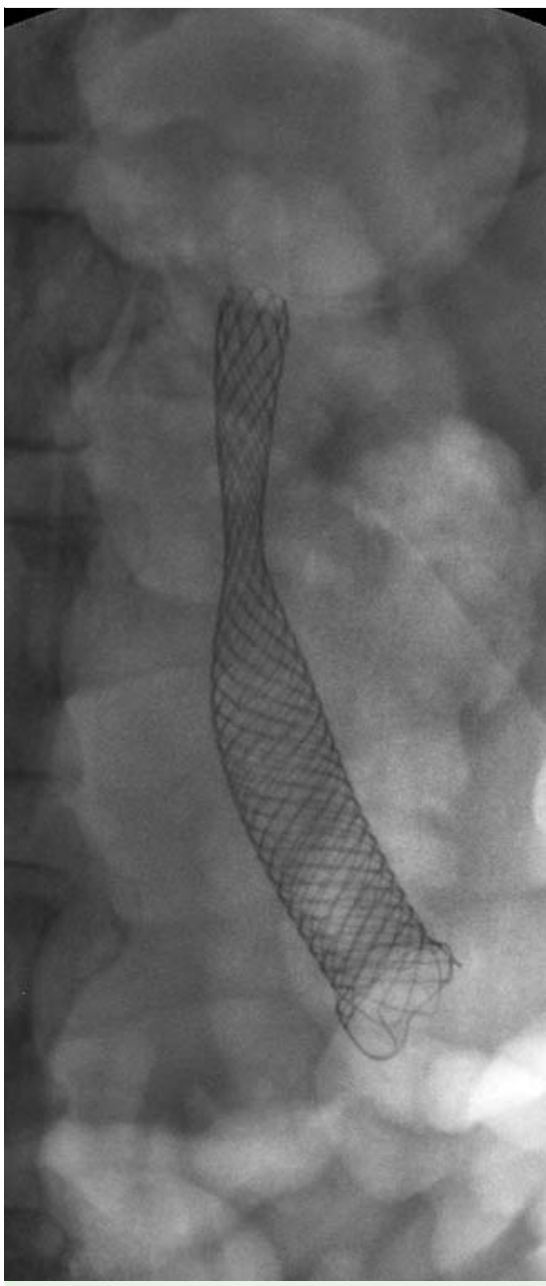

Fig. 2 A biliary fully covered self-expandable metal stent was placed in the common bile duct to stop the bleeding.

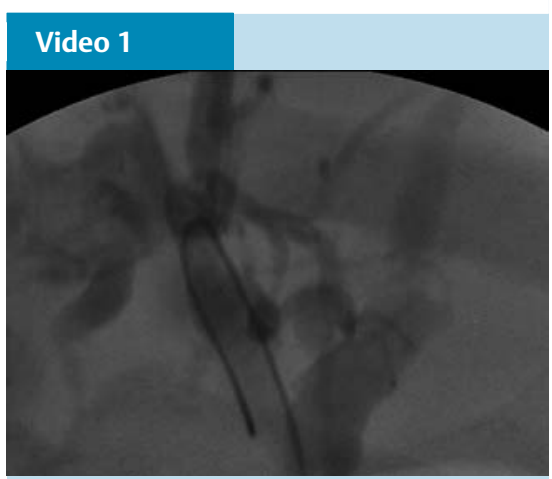

Torrential bleeding coming from the papilla, after a small biliary sphincterotomy and stone extraction in a patient with situs inversus totalis, a thrombosed portal vein with cavernoma, and common bile duct/common hepatic duct obstruction. A biliary fully covered selfexpandable metal stent was placed and occluded with a controlled radial expansion balloon to stop the bleed. 

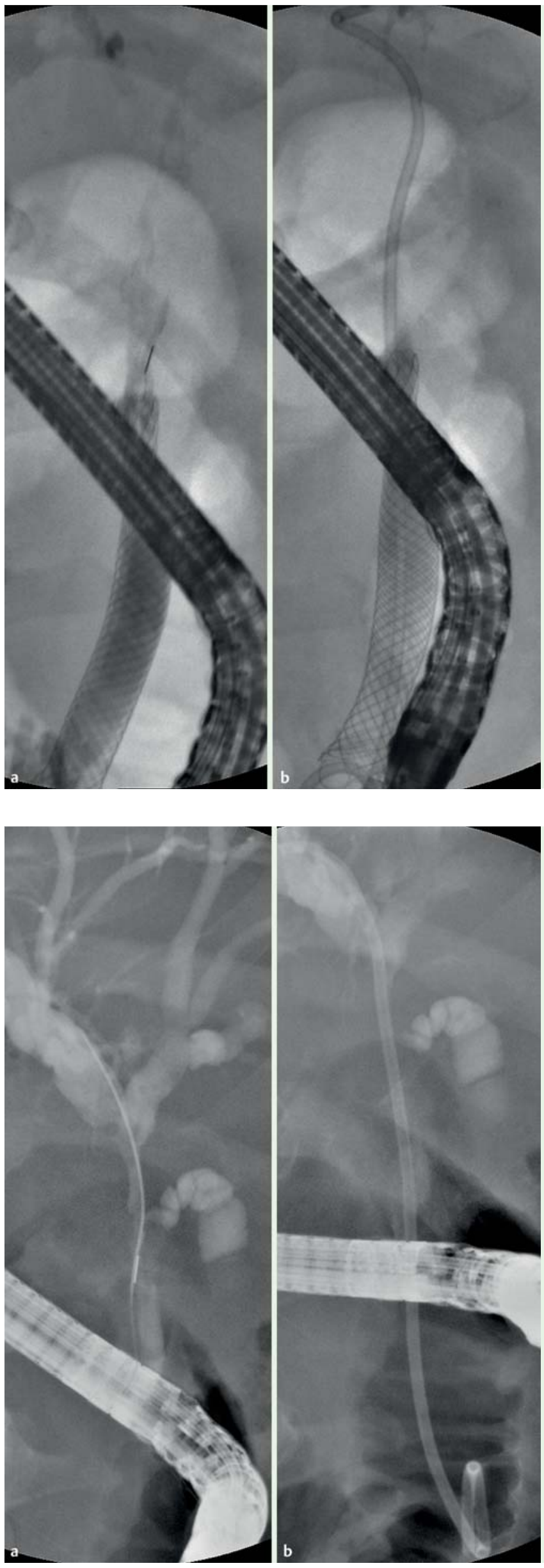

Fig. 3 a Cholangiogram 2 days after bleeding, showing filling defects (clots) occluding the biliary ducts and the selfexpandable metal stent. b A plastic stent was then inserted into the metal stent.

Fig. 4 a Cholangiogram 3 months later showing persistent common hepatic duct compression after removal of metal and plastic stents. b Another plastic stent was therefore placed.
Endoscopy_UCTN_Code_CPL_1AK_2AF

\section{Competing interests: None}

\section{Sundeep Lakhtakia², Rajesh Gupta², Domenico Galasso ${ }^{1}$, Mohan Ramchan- dani $^{2}$, Palle Manohar Reddy ${ }^{2}$, Guduru V. $\mathbf{R a o}^{3}$, Nageshwar D. Reddy ${ }^{2}$}

${ }^{1}$ Digestive Endoscopic Unit, A. Gemelli Hospital, Università Cattolica del Sacro Cuore, Rome, Italy

${ }^{2}$ Gastroenterology and Therapeutic Endoscopy Department, Asian Institute of Gastroenterology, Hyderabad, India

${ }^{3}$ Surgery Department, Asian Institute of Gastroenterology, Hyderabad, India

\section{References}

1 Fiocca F, Donatelli G, Ceci Vet al. ERCP in total situs viscerum inversus. Case Rep Gastroenterol 2008; 2: 116-120

2 Coban S, Yuksel I, Kucukazman M et al. Successful ERCP in a patient with situs inversus. Endoscopy 2014; 46 (Suppl. 01): E222

3 Goenka MK, Harwani Y, Rai V et al. Fully covered self-expandable metal biliary stent for hemobilia caused by portal biliopathy. Gastrointest Endosc 2014; 80: 1175

\section{Bibliography}

DOI http://dx.doi.org/

10.1055/s-0034-1392316

Endoscopy 2015; 47: E335-E336

(c) Georg Thieme Verlag KG

Stuttgart · New York

ISSN 0013-726X

\section{Corresponding author}

\section{Sundeep Lakhtakia, MD}

Gastroenterology and Therapeutic Endoscopy Department

Asian Institute of Gastroenterology

6-3-661, Somajiguda, Hyderabad

Telangana 500082

India

Fax: +91-40-2332 4255

drsundeeplakhtakia@gmail.com 